\title{
Respiratory Epithelial Cell Expression of Human Transforming Growth Factor- $\alpha$ Induces Lung Fibrosis in Transgenic Mice
}

\author{
Thomas R. Korfhagen, Robert J. Swantz, Susan E. Wert, Julia M. McCarty, \\ Carol B. Kerlakian, Stephan W. Glasser, and Jeffrey A. Whitsett \\ Children's Hospital Medical Center, Division of Pulmonary Biology, Cincinnati, Ohio 45229
}

\begin{abstract}
Increased production of EGF or TGF- $\alpha$ by the respiratory epithelial cells has been associated with the pathogenesis of various forms of lung injury. Growth factors and cytokines are thought to act locally, via paracrine and autocrine mechanisms, to stimulate cell proliferation and matrix deposition by interstitial lung cells resulting in pulmonary fibrosis. To test whether TGF- $\alpha$ mediates pulmonary fibrotic responses, we have generated transgenic mice expressing human TGF- $\alpha$ under control of regulatory regions of the human surfactant protein $\mathrm{C}$ (SP-C) gene. Human TGF- $\alpha$ mRNA was expressed in pulmonary epithelial cells in the lungs of the transgenic mice. Adult mice bearing the SP-C-TGF- $\alpha$ transgene developed severe pulmonary fibrosis. Fibrotic lesions were observed in peribronchial, peribronchiolar, and perivascular regions, as well as subjacent to pleural surfaces. Lesions consisted of fibrous tissue that included groups of epithelial cells expressing endogenous SP-C mRNA, consistent with their identification as distal respiratory epithelial cells. Peripheral fibrotic regions consisted of thickened pleura associated with extensive collagen deposition. Alveolar architecture was disrupted in the transgenic mice with loss of alveoli in the lung parenchyma. Pulmonary epithelial cell expression of TGF- $\alpha$ in transgenic mice disrupts alveolar morphogenesis and produces fibrotic lesions mediated by paracrine signaling between respiratory epithelial and interstitial cells of the lung. (J. Clin. Invest. 1994. 93:1691-1699.) Key words: pulmonary fibrosis $\bullet$ transforming growth factor- $\alpha \cdot$ paracrine effects $\bullet$ autocrine effects $\bullet$ lung cell gene expression
\end{abstract}

\section{Introduction}

Control of cellular proliferation and gene expression during lung development and after lung injury is thought to involve complex autocrine/paracrine interactions between epithelial and interstitial cells in pulmonary tissues. There is increasing evidence that epidermal growth factor family members, in-

Address correspondence to Thomas R. Korfhagen, M.D., Ph.D., Children's Hospital Medical Center, Division of Pulmonary Biology, TCHRF, 3333 Burnet Avenue, Cincinnati, OH 45229-3039.

This work was presented in part at the North American Cystic Fibrosis Conference, 15-18 October 1992, Washington, DC, and published (1992. Pediatr. Pulmonol. Suppl. 8:281). It was also presented in part at the Annual Meeting of the American Thoracic Society, 16-19 May 1993, San Francisco, CA, and published (1993. Am. Rev. Respir. Dis. 147:A277).

Received for publication 13 September 1993 and in revised form 12 November 1993

J. Clin. Invest.

(c) The American Society for Clinical Investigation, Inc.

0021-9738/94/04/1691/09 \$2.00

Volume 93, April 1994, 1691-1699 cluding EGF and TGF- $\alpha$, are mediators of both lung morphogenesis and repair. EGF and TGF- $\alpha$ are closely related polypeptides produced by a variety of cells, have pleiotropic effects on cell proliferation and gene expression, and bind to the EGF receptor (EGFR), ${ }^{1}$ which transmits intracellular signals in a variety of cell types (1-7). In the lung, TGF- $\alpha$ and EGF have been localized to respiratory epithelial cells by immunohistochemistry. EGF is detected in the conducting airway epithelial cells of the developing mouse, rat, and human lung (8-11), and in alveolar type II, bronchiolar, ciliated, and nonciliated cells in the rat lung (12). TGF- $\alpha$ has also been identified in fetal human and rat lung (13-15). EGF receptors are localized in the conducting airway epithelium of fetal ovine lung, suggesting that the airway epithelium is a target site for EGF or TGF- $\alpha$ action (16). Mesenchymal cells of the developing mouse lung express preproEGF mRNA and may therefore serve as cellular targets for EGF or TGF- $\alpha$ (17).

There is increasing evidence that EGF and TGF- $\alpha$ alter branching morphogenesis and differentiation of the developing mouse lung $(8,18)$. In vivo administration of EGF causes epithelial cell hyperplasia in fetal and neonatal lambs (19), and increases phospholipid inclusions in type II epithelial cells in fetal rabbits and monkeys in vivo $(20,21)$. Surfactant proteinA mRNA and SP-A protein production is increased in human fetal lung explants treated with EGF in vitro (22).

EGF or TGF- $\alpha$ may also play a role in cellular responses after lung injury. EGF is detected in cells of the conducting airways of infants dying of chronic lung disease, but it is not detected in the lungs of infants dying from other causes (9). Lipopolysaccharide endotoxin induces the production of TGF$\alpha$ by alveolar macrophages, supporting a potential role for TGF- $\alpha$ in response to infection (23). TGF- $\alpha$ and EGFR expression by pulmonary epithelial cells increases after bleomycin-induced lung injury (24).

While a variety of experiments support the role of epidermal growth factor related peptides in lung morphogenesis and repair, their direct effects on lung architecture and the mechanisms by which these signals are transduced among pulmonary cells has not been determined. The present study used transgenic mice to demonstrate the effects of epithelial cell expression of TGF- $\alpha$ on lung morphogenesis in vivo, and to test whether the effects of TGF- $\alpha$ are mediated by paracrine interactions between epithelial and interstitial cells of the lung.

\section{Methods}

Reagents and bacterial strains. Restriction endonucleases and enzymes used in cloning reactions were purchased from New England

1. Abbreviations used in this paper: CAT, chloramphenicol acetyltransferase; CC-10, Clara Cell-10 kD; hGH, human growth hormone; MT, metallothionein; SP-A, surfactant protein-A; SP-C, surfactant proteinC; SSPE, sodium chloride sodium phosphate buffer. 
Biolabs (Beverly, MA). Nick translation was performed using a kit from Bethesda Research Laboratories (Gaithersburg, MD). Plasmids were cloned and propagated in Escherichia coli $\mathrm{DH} 5 \alpha \mathrm{F}^{\prime}$.

Preparation of surfactant protein $C$-human TGF- $\alpha$-human growth hormone (SP-C-hTGF- $\alpha-h G H)$ and identification of transgenic mice. The plasmid phTGF1-10-925 was obtained from the American Type Culture Collection (Rockville, MD). SP-C-hGH was constructed by cloning the 3.7-kb flanking sequences of the human SP-C sequences into the HindIII site of PUC18-hGH (25). A 0.93-kb EcoRI fragment containing the coding sequence for human TGF- $\alpha$ was isolated, BgIII linkers attached, and cloned into the BamHI site of SP-C-hGH to generate SP-C-hTGF- $\alpha$-hGH. A 6.6-kb Ndel/EcoRI fragment was microinjected in the male pronucleus of fertilized FVB/N mouse eggs to generate transgenic mice, which were identified from genomic tail DNA by Southern blot analysis with nick-translated $0.93-\mathrm{kb}$ TGF- $\alpha$ cDNA as probe using previously described Methods, except that final washes were in $0.2 \times \mathrm{SSC}, 0.1 \% \mathrm{SDS}$ at $65^{\circ} \mathrm{C}(25)$. The studies on transgenic mice were reviewed and approved by the Institutional Animal Care and Use Committee of the Children's Hospital Research Foundation. Northern blot analysis was performed using ${ }^{32} \mathrm{P}$-labeled human TGF- $\alpha$ cDNA as previously described (25) with the following modifications: Hybridization was in $50 \%$ formamide, $2.5 \%$ Denhardt's $(1 \times$ Denhardt's is $0.02 \%$ polyvinylpyrrolidane, $0.02 \%$ Ficoll, $0.02 \%$ bovine serum albumin ), $5 \times$ sodium chloride sodium phosphate EDTA buffer (SSPE) $(1 \times$ SSPE is $0.18 \mathrm{M} \mathrm{NaCl}, 10 \mathrm{mM}$ sodium phosphate, $\mathrm{pH} 7.7$, $1 \mathrm{mM}$ EDTA), $1 \%$ SDS, $10 \%$ Dextran sulfate, and $200 \mu \mathrm{g} / \mathrm{ml}$ salmon sperm DNA. Final wash was in $0.2 \times \mathrm{SSPE}, 0.1 \%$ SDS at $55^{\circ} \mathrm{C}$.

Tissue preparation, stains, and in situ hybridization. Mice were killed by intraperitoneal injection with pentobarbital. Lungs were inflation fixed by gravity for $1 \mathrm{~min}$ at $25 \mathrm{~cm}$ of pressure with $4 \%$ paraformaldehyde in phosphate-buffered saline, $\mathrm{pH}$ 7.2. Specimens were cryoprotected in 30\% sucrose, embedded in molds, and frozen over liquid nitrogen. Cryostat sections of 8-10 $\mu \mathrm{m}$ were collected on silane-coated slides, postfixed in $4 \%$ paraformaldehyde, dehydrated, and stored at $-80^{\circ} \mathrm{C}$. Tissues were stained with hematoxylin-eosin, by Verhoeff's method for detection of elastin fibers, or by Masson's trichrome method for the detection of collagen fibers according to previously described protocols (26).

For in situ hybridization, the slides were rehydrated, digested with $20 \mu \mathrm{g} / \mathrm{ml}$ proteinase $\mathrm{K}$, acetylated in $0.25 \%$ acetic anhydride in $0.1 \mathrm{M}$ triethanolamine, and dehydrated through a graded series of alcohols. Riboprobes were synthesized from pGEM-3Z or $4 Z$ vectors containing murine SP-C cDNA or rat Clara Cell-10 kD protein (CC-10) cDNA as described previously (27). A 30-bp antisense human TGF- $\alpha$ oligonucleotide was obtained from $R$ \& D Systems, Inc. (Minneapolis, MN) and was end-labeled with ${ }^{35} \mathrm{~S}-\mathrm{dATP}$. A total of $1 \times 10^{6} \mathrm{cpm}$ in a $15-\mu \mathrm{l}$ vol was applied to sections, and hybridized for $15-18 \mathrm{~h}$ at $55^{\circ} \mathrm{C}$ for the riboprobes or $37^{\circ} \mathrm{C}$ for the oligonucleotide probes. Sections hybridized with riboprobes were washed at $65^{\circ} \mathrm{C}$ in $50 \%$ formamide, $2 \times \mathrm{SSC}, 10$ $\mathrm{mM} \mathrm{DTT}$ for $30 \mathrm{~min}$, then treated with $20 \mu \mathrm{g} / \mathrm{ml} \mathrm{RNase} \mathrm{A} \mathrm{and} 5 \mathrm{U} / \mathrm{ml}$ RNase $\mathrm{T} 1$ at $37^{\circ} \mathrm{C}$ for $30 \mathrm{~min}$. A second wash was then performed at $65^{\circ} \mathrm{C}$ in $50 \%$ formamide $2 \times \mathrm{SSC}, 10 \mathrm{mM}$ DTT for $30 \mathrm{~min}$ followed by two washes in $2 \times \mathrm{SCC}$ and $0.1 \times \mathrm{SSC}$ at room temperature for $15 \mathrm{~min}$ each. For the oligonucleotide in situ hybridization, slides were washed for $1 \mathrm{~h}$ at room temperature in $2 \times \mathrm{SSC}, 1 \times \mathrm{SSC}$ twice, and $0.5 \times \mathrm{SSC}$, followed by two washes at $55^{\circ} \mathrm{C}$ in $0.5 \times \mathrm{SSC}$ for $45 \mathrm{~min}$. All slides were dehydrated through a graded series of alcohols, dipped in 50\% Ilford $\mathrm{K} 5$ nuclear track emulsion, and autoradiographed for $5-21 \mathrm{~d}$ at $4^{\circ} \mathrm{C}$. Slides were developed with Kodak D19 developer at $16^{\circ} \mathrm{C}$. Sections were counterstained with hemotoxylin and eosin. Specificity of riboprobes and the oligonucleotide probe were established by hybridization with sense probes or a 30 -bp randomer oligonucleotide.

\section{Results}

Identification of transgenic mice bearing $T G F-\alpha$ chimeric gene. Six independent founder mice bearing the human SP-C-TGF$\alpha$-hGH transgene were produced. Human growth hormone se- quences were included to provide introns. The presence of introns enhances transcription in transgenic mice (28). Southern blot analysis of genomic DNA from the transgenic mice demonstrated the presence of diagnostic fragments from the exogenous DNA after digestion with PstI (Fig. $1 A$ ). In all founder animals, a PstI fragment of $\sim 1.4 \mathrm{~kb}$ was detected, consistent with that expected from the inserted transgene. Smaller PstI fragments predicted from the restriction map of the transgene
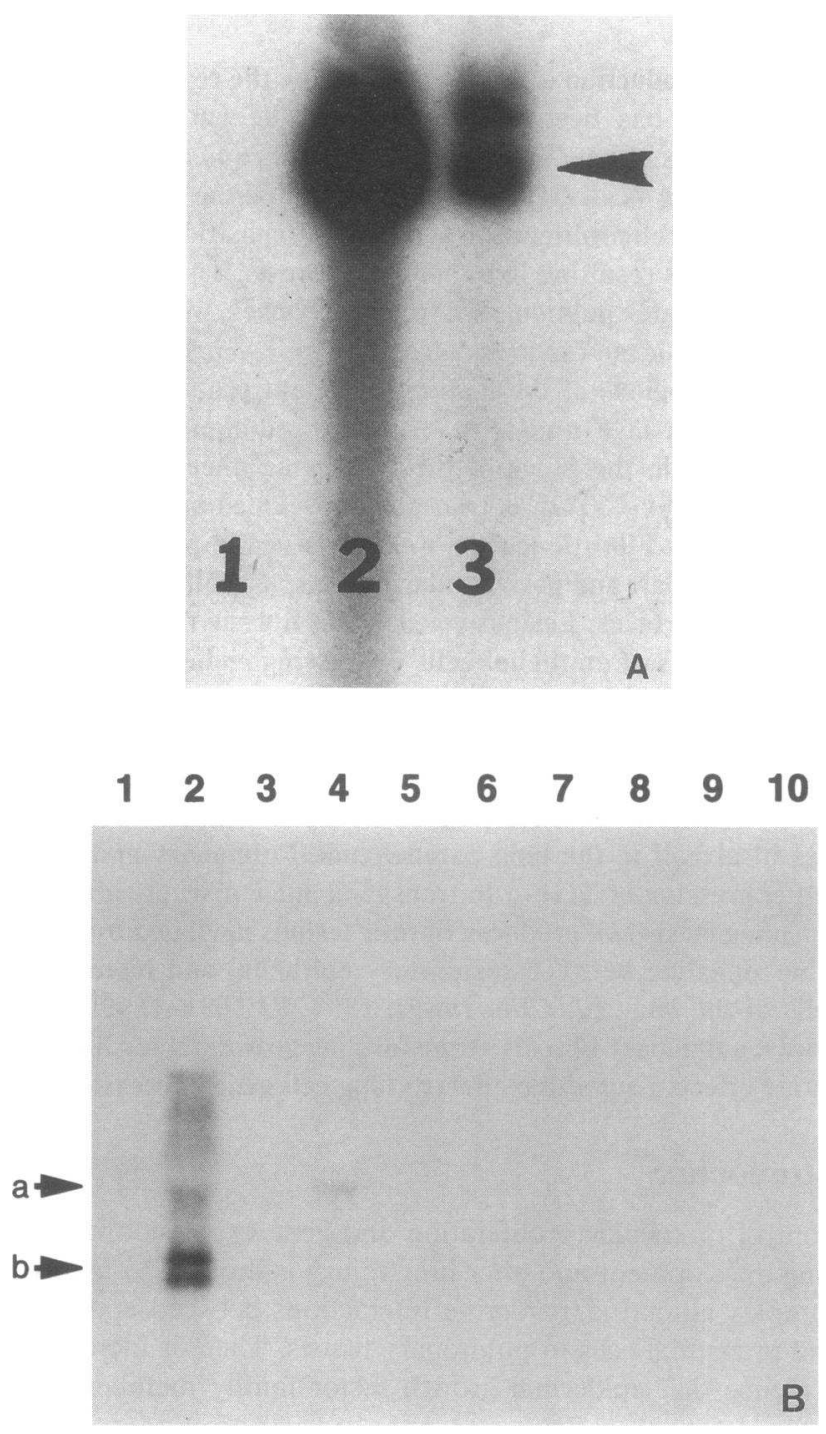

Figure 1. Southern and northern blot analysis of transgenic mice. $(A)$ Representative autoradiograms of Southern blots are presented. Each lane was loaded equally with total genomic DNA digested with PstI and probed with the human TGF- $\alpha$ cDNA as described in Methods. Lane 1 is from a nontransgenic mouse, lane 2 is from the $\mathrm{H} 8$ mouse, and lane 3 from the $\mathrm{H} 9$ mouse. The position of an expected diagnostic fragment of $\sim 1.4 \mathrm{~kb}$ is marked with an arrowhead. The band detected above the 1.4-kb fragment in lane 3 is probably caused by partial digestion with PstI, and was only seen with the H9 DNA. $(B)$ RNA was prepared from tissues of an F2 offspring of the E1 line. Approximately $20 \mu \mathrm{g}$ of total RNA was loaded in each lane. Odd numbered lanes are from a nontransgenic mouse, and even numbered lanes from the transgenic mouse. Lanes 1 and 2 , lung; lanes 3 and 4, brain; lanes 5 and 6, liver; lanes 7 and 8 testes; lanes 9 and 10 , heart. The arrow marked $a$ depicts an $\sim 2.0-\mathrm{kb}$ band, and the arrow marked $b$ depicts the position of an $\sim 1$.0-kb hTGF- $\alpha$ mRNA species. 
were also detected (data not shown). The six independent founder transgenic mice and several offspring were available for histological study and were compared with five nontransgenic mice of comparable age. Two of the founder transgenic mice ( 43 and 44 ) were housed under pathogen-free conditions. Representative mice in rooms for the other transgenic mice and the control mice had positive serology for mouse hepatitis virus, but not Sendai virus. Transgenic mice H8, G2, E1 (F0), and $E 1(F 1)$ appeared normal at the time of death, while animal H9 had ruffled fur and was lethargic at the time of death. By 3 wk of age, transgenic mice 43 and 44 appeared smaller than age-matched littermates. Mouse 44 was noted to be cyanotic before death. Except for those abnormalities noted in the lung, there were no abnormalities detected by gross examination of any of the organs of the transgenic mice at sacrifice or at death. The histological characteristics of the lungs of the transgenic mice are listed in Table I.

Northern blot analysis of total RNA from a transgenic mouse of the $\mathrm{E} 1$ line (Fig. $1 \mathrm{~B}$ ) demonstrated the presence of a variety of sizes of transcript in the lung with the prominent bands a doublet at $\sim 1.0 \mathrm{~kb}$. Variability in transcript size may result from alternate splicing or termination in the growth hormone sequences. Messenger RNA hybridizing to human TGF$\alpha$ probe of $\sim 2.0 \mathrm{~kb}$ was also detected in the brain but was much less prominent than the lung transcripts. Human TGF- $\alpha$ transcripts were not detected in other tissues examined.

Histopathology of the lungs from transgenic animals. Characteristic hypercellular fibrotic lesions were detected in lungs from all lines of the transgenic mice (Fig. 2). Fibrotic lesions were not observed in five control mice or in lungs from other transgenic mice bearing 3.7 SP-C-driven chimeric genes maintained in our mouse colonies. Regions of marked hypercellularity were observed in the lung interstitium and were especially prominent near pulmonary vessels and bronchioles (Fig. $2 B$ ). The fibrotic lesions generally consisted of fibroblastoid interstitial cells, but also included distinct cuboidal cells that were readily distinguished by their red staining cytoplasm (Fig. $2 C$ ). Cuboidal cells were generally observed in linear arrays, clusters, or organized into acini within the fibrotic lesions. There were no distinguishing abnormalities in the alveolar interstitium or in alveolar, bronchiolar, or bronchial epithelium of the transgenic mice. Endothelial and vascular tissues also appeared unaltered by light microscopic analysis. While the fibrotic lesions were observed in all of the transgenic lines examined, the size and distribution of the fibrotic lesions varied among the transgenic mice. The distribution of lesions in line E1(F0) was patchy, with some sections having no detectable alterations. The lesions in the $\mathrm{E} 1(\mathrm{~F} 1)$ were more severe and were observed throughout the lung. El(F0) transmitted the transgene to three of five males and no females of the F1 generation. Subsequent generations transmitted the transgene to $100 \%$ of males but males only, consistent with Y-linked inheritance. E1(F0) is likely to be mosaic, which may explain the patchy distribution of the lesions compared to the F1 generation. In contrast, the lesions in E43(F0) were confined to the left lung, while the right lung was normal by light microscopy.

The pleural surfaces of the lungs from the transgenic mice were generally thickened compared to those of nontransgenic animals (Fig. $2 \mathrm{D}$ ). The distribution and severity of the pleural lesions varied among the transgenic mice and were generally more severe in those animals having the larger central fibrotic lesions. Although inflation fixed under identical conditions, alveolar air spaces were larger in the lungs from all the transgenic lines examined, as compared to the lungs of the nontransgenic controls when assessed by light microscopy (Figs. 2 and 4). There was, however, no apparent thickening of the alveolar interstitium nor accumulation of debris within these air spaces. Mononuclear cells were seen in the airspaces of both transgenic and nontransgenic animals and consisted primarily of alveolar macrophages (Fig. $2 \mathrm{D}$ ). Macrophages were in general more abundant in the lungs of the transgenic mice compared to controls. Groups of mononuclear cells typical of bronchial associated lymphocytes were observed near bronchioles and, more rarely, at pleural surfaces in lungs of both transgenic and nontransgenic mice. Polymorphonuclear cells were not observed in the lungs of either transgenic or control mice. Collections of lymphocytes, consistent with lymph nodules, were identified subjacent to bronchiolar epithelium in some sections of transgenic and nontransgenic lungs.

Collagen deposition in the fibrotic lesions. Representative sections of the lungs were prepared with Masson trichrome stain (Fig. 2). Masson trichrome stain is a histological method of distinguishing collagen deposition from accumulation of smooth muscle cells (26). Abundant, blue staining collagen fibrils were noted in both central and peripheral lesions of the transgenic mice, consistent with the interpretation that fibrotic

Table I. Histological Characteristics of Lungs from the 3.7 SP-C-TGF- $\alpha$ Transgenic Mice

\begin{tabular}{cccccc}
\hline Line (Generation) & Age & Sex & $\begin{array}{c}\text { Central } \\
\text { lesions }\end{array}$ & $\begin{array}{c}\text { Pleural } \\
\text { thickening }\end{array}$ & $\begin{array}{c}\text { Elastic fiber } \\
\text { abnormalities }\end{array}$ \\
\hline & $m o$ & & & & \\
H8 (F0) & 14 & F & Present & Present & Present \\
alveoli
\end{tabular}

Transgenic mice are identified with laboratory designations. F0 indicates a founder mouse, $\mathrm{F} 1$ is offspring of the first generation. Histological characteristics are described in the text. ND, not determined. Lungs from five age-matched control FVB/N mice, housed under identical conditions, were without fibrotic lesions. 

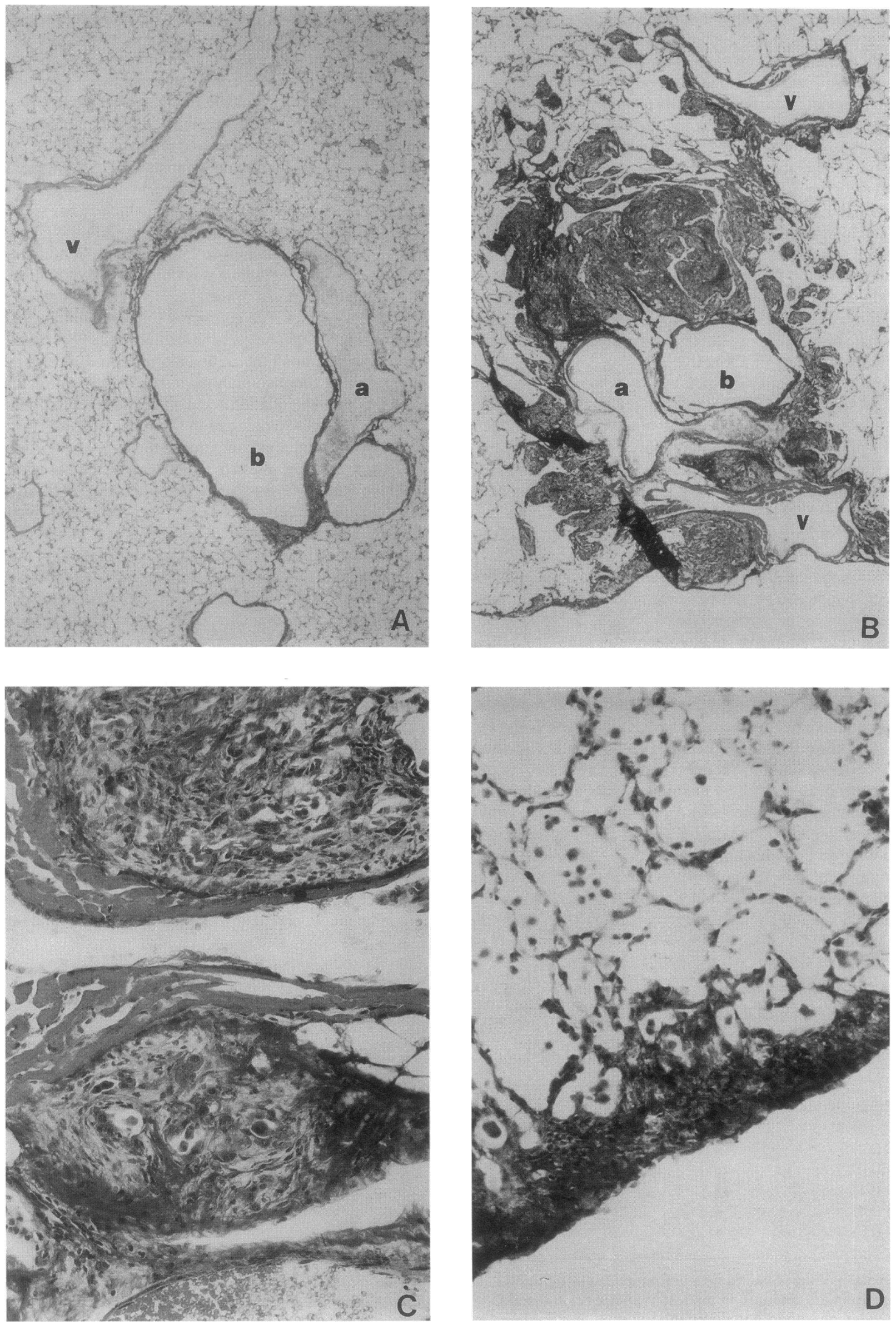

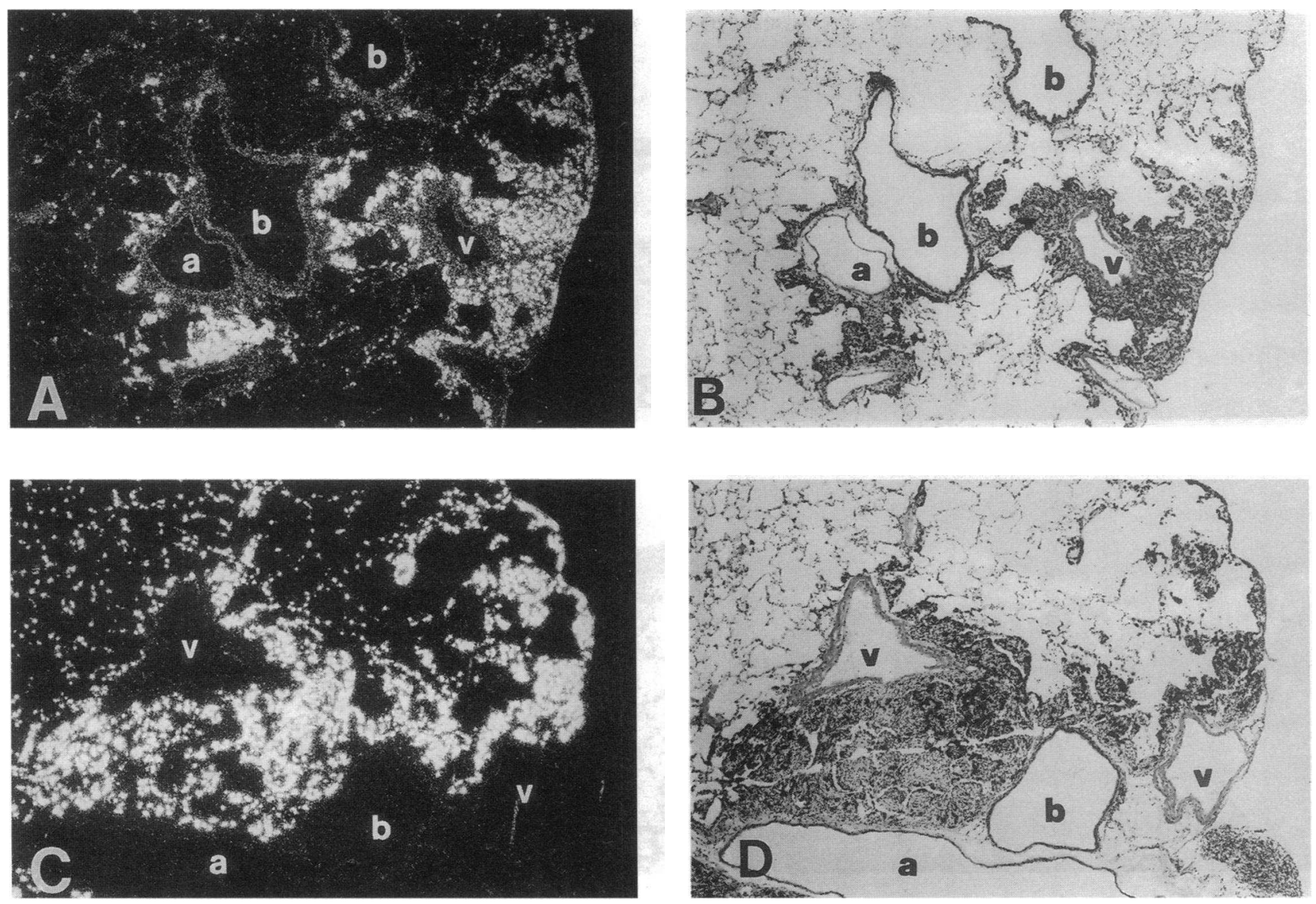

Figure 3. $(A-D)$ Detection of human TGF- $\alpha$ and murine SP-C mRNA by in situ hybridization. Dark-field photomicrograph of a central fibrotic lesion hybridized to the hTGF- $\alpha$ oliogonucleotide from the $\mathrm{H} 8$ mouse is seen in $A$. In situ hybridization was performed with a human TGF- $\alpha$ oligomer $(A)$ and endogenous murine SP-C $(C) . B$ and $D$ are the corresponding bright-field photomicrographs. Hybridization signals for both human TGF- $\alpha$ and murine SP-C were detected in alveolar epithelial cells in lung parenchyma and adjacent to and within the fibrotic lesions. A 30-nucleotide random oligomer probe was used as a control demonstrating no specific labeling (not shown). Human TGF- $\alpha$ mRNA was not detected in the nontransgenic mice (not shown) under these conditions. Bright-field sections were counterstained with hematoxylin and eosin. $a$, artery; $b$, bronchiole; $v$, vein. $\sim \times 29$.

lesions are forming. There was no detectable collagen deposition in the peripheral-alveolar regions in the lungs of the nontransgenic animals.

Alterations of elastin fibers. Disruption of elastin fiber organization is characteristic of various forms of lung injury and has been described in both bronchopulmonary dysplasia (29) and emphysema. Elastin fibers were altered in the perihilar, hypercellular lesions, as well as in the alveolar, bronchiolar, and pleural regions of the lungs of the $\mathrm{H} 8$ and $\mathrm{H} 9$ mice (data not shown). Elastin fibers adjacent to bronchiolar structures were shorter and appeared blunted compared to those from controls. In contrast, elastin fiber staining was not altered in vessel walls. Elastin fiber distribution in three mice $(G 2$, $\mathrm{E} 1[\mathrm{~F} 0]$, and $\mathrm{E} 1 \mathrm{~F} 1]$ ) was similar to that of the control lungs.

Localization of human TGF- $\alpha$ mRNA in lungs of transgenic animals. An oligomer specific for human TGF- $\alpha$ mRNA was used to detect TGF- $\alpha$ transcripts by in situ hybridization in lungs of the $\mathrm{H} 8$ and $\mathrm{H} 9$ mice. Human TGF- $\alpha$ transcripts were confined to epithelial cells in alveolar regions and in cuboidal cells within central fibrotic lesions of lungs from the transgenic mice (Fig. 3, $A$ and $B$ ). TGF- $\alpha$ mRNA-expressing cells were also abundant in regions subjacent to the thickened peripheral lesions (Fig. 4, $A$ and $B$ ). The distribution of the TGF- $\alpha$ transcripts was similar to that of endogenous murine SP-C transcripts (Fig. 3, $C$ and $D$, and Fig. 4, $C$ and $D$ ). No hybridization signals were detected in lungs from control mice using the human TGF- $\alpha$ oligomer (Fig. 4, $E$ and $F$ ). A 30-nucleotide randomer failed to hybridize to either control or transgenic lungs (data not shown).

Identification of respiratory epithelial cells in fibrotic lesions. In situ hybridization analysis with epithelial lung cellspecific mRNAs was used to further characterize the cuboidal cells located within central fibrotic lesions. Murine SP-C mRNA is known to be selectively expressed in type II cells,

Figure 2. $(A-D)$ Central and peripheral fibrotic lesions assessed with trichrome staining of lung tissue from SP-C-TGF- $\alpha$ transgenic mice. $A$ represents normal bronchial, vascular, and alveolar architecture in control lung. Typical fibrotic lesions containing abundant blue-staining collagen deposition from the $\mathrm{H} 8$ transgenic mouse lung are represented in $B$. $C$ represents an enlarged view of the cuboidal epithelial cells (arrows) found within the central fibrotic lesion noted in $B$. Representative pleural lesion is seen in $D$. Note enlarged alveolar spaces and mononuclear cells. $a$, artery; $b$, bronchiole; $v$, vein. $\sim \times 43$ in $A$ and $B, \sim \times 212$ in $C$ and $D$. 

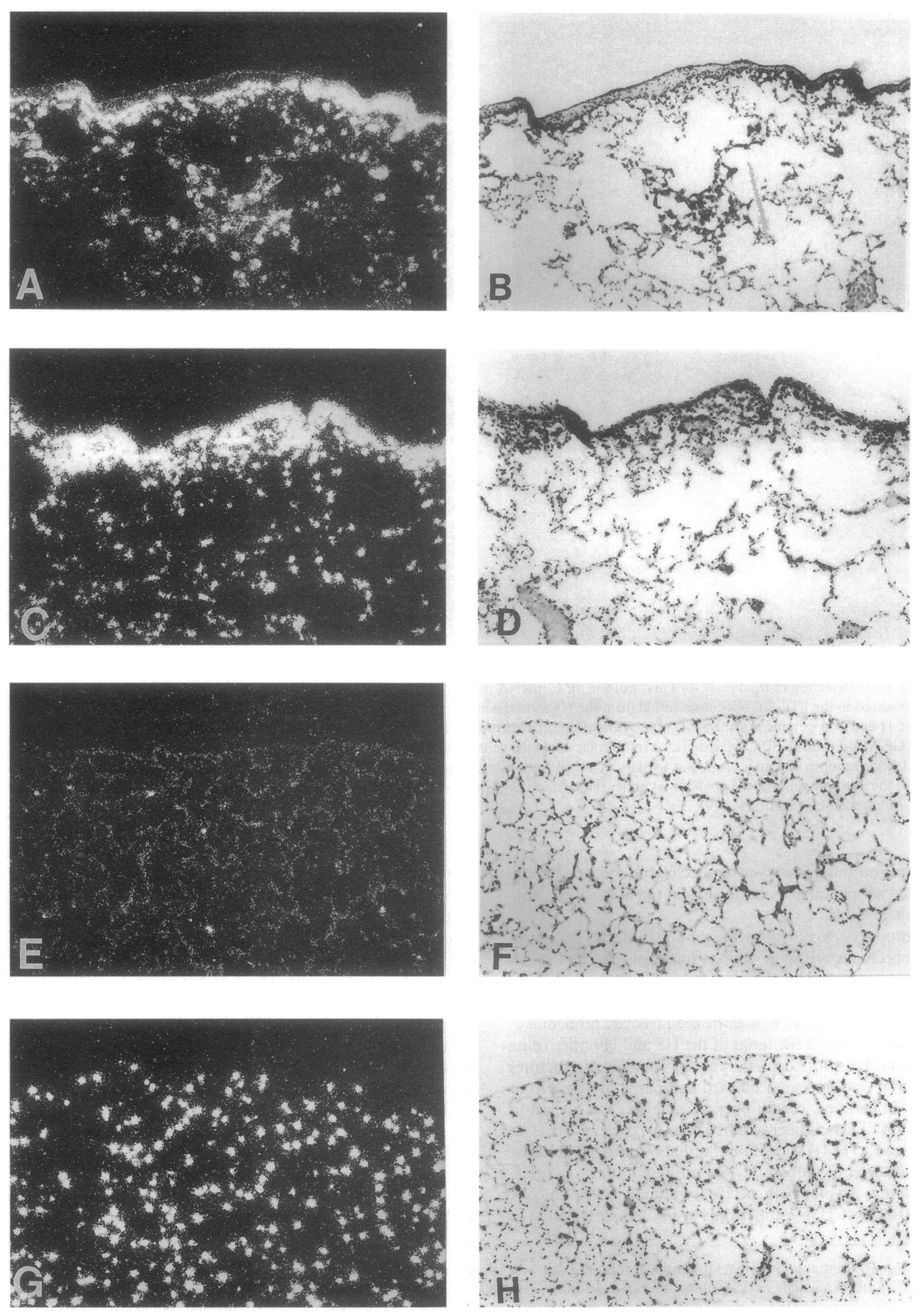
while CC-10 mRNA is expressed in bronchiolar, bronchial, and tracheal cells in the murine lung (27). Endogenous SP-C mRNA was observed in alveolar type II epithelial cells in peripheral regions of the lungs from the transgenic mice consistent with the pattern of expression seen in nontransgenic animals (Fig. 4, $C$ and $G$ ). The murine SP-C probe also hybridized to epithelial cells within the central fibrotic regions from the lungs of transgenic mice (Fig. $3 C$ ). Murine CC-10 mRNA was not detected in epithelial cells within the interstitial lesions, but was readily detected in epithelial cells of the conducting airways of both transgenic and nontransgenic animals (data not shown ). Cells expressing murine SP-C mRNA were also concentrated near the pleural fibrotic lesions in a pattern similar to that of human TGF- $\alpha$ mRNA produced by the transgene (Fig. $4 C)$.

\section{Discussion}

Lung epithelial cell-specific expression of human TGF- $\alpha$ was directed by promoter-enhancer elements derived from the $5^{\prime}$ region of the human SP-C gene producing severe pulmonary fibrosis in transgenic mice. This study demonstrates that local production of TGF- $\alpha$ affects lung morphogenesis and/or remodeling, supporting the concept that paracrine interactions between respiratory epithelial cells and the pulmonary interstitium can produce lung fibrosis.

The marked fibroproliferative abnormalities detected in the human SP-C-TGF- $\alpha$ transgenic mice were confined to the lung, consistent with the expression of the exogenous TGF- $\alpha$ mRNA in distal respiratory epithelial cells as demonstrated by in situ hybridization of the transgenic animals. The pulmonary distribution of the expression of the transgene was similar to that of the endogenous SP-C mRNA and to that generated by the human 3.7 SP-C promoter-enhancer previously reported from this laboratory $(25,27,30,31)$. In the current study, human TGF- $\alpha$ mRNA was readily detected by Northern blot analysis in the lung and was absent from other tissues, except for a larger and less abundant transcript detected in the brain. The relative abundance and distribution and expression from this SP-C promoter-enhancer element has varied in the lungs of transgenic lines produced by our laboratory. In general, expression of transgenes has been confined to respiratory epithelium with the human 3.7 SP-C sequences. However, expression of simian virus 40 large $T$ antigen was detected at low levels in the brains of transgenic mice bearing the human 3.7 SP-C simian virus 40 large $T$ antigen construct, as reported previously (31). The reason for variability in tissue expression of the SP-C sequences is not known, but may involve positional effects dependent on the sites of integration of the transgene. Chloramphenicol acetyltransferase (CAT) mRNA was detected as early as day 10 of gestation in the human 3.7 SP-C-CAT transgenic mice (27), supporting the likelihood that the expression of TGF- $\alpha$ from this element may have influenced lung growth and development throughout its morphogenesis.
The lack of detectable effects in other organs supports the concept that the local production, rather than systemic release of TGF- $\alpha$, produced the fibroproliferative responses noted in the interstitium of the lungs from the SP-C-TGF- $\alpha$-bearing animals. Jhappan et al. (32) and Sandgren et al. (33) generated transgenic mice expressing TGF- $\alpha$ under control of the metallothionein (MT) promoter that produced ductal metaplasia with fibrosis in the pancreas and epithelial hyperplasia and/or carcinoma in the liver, mammary glands, and coagulation glands. While human TGF- $\alpha$ mRNA was detected in lung tissue of the MT-TGF- $\alpha$ by RNAse protection assay, pulmonary lesions were not detected in those transgenic animals (33). Differences in the level and cellular sites of expression of human TGF- $\alpha$ in the lungs of the MT driven as compared to the SP-C-driven TGF- $\alpha$ may have contributed to the differences between the present study and those of Jhappan et al. (32) and Sandgren et al. (33). Both the lung and pancreas respond to the TGF- $\alpha$ signal by the production of fibrotic lesions that were not detected in other tissues $(32,33)$. The precise mechanism accounting for differences in tissue response has not been determined, but differences in microenvironment, fibroblast subtypes, or fibroblast EGFR expression are likely to be involved.

Fibrotic lesions were prominent in central perihilar, peribronchiolar, and peribronchial regions. In these regions, cells expressing human TGF- $\alpha$ mRNA were detected in a pattern similar to that of the SP-C-expressing cells. Thus, cells with type II epithelial cell characteristics were producing TGF- $\alpha$ and were surrounded by fibrotic regions. Bronchiolar cells did not contain human TGF- $\alpha$ mRNA as detected by in situ hybridization. In more peripheral areas of the lung parenchyma, human TGF- $\alpha$ mRNA was detected in some epithelial cells in the absence of alveolar thickening or fibrosis. While the mechanism involved in this heterogeneity is unclear at present, it is possible that interstitial cells involved in the fibroproliferative response may be sensitive to the action of TGF- $\alpha$ in the central and pleural lesions, but less sensitive in other regions of the lung parenchyma. Production of human TGF- $\alpha$ in the developing and conducting airway of the transgenic animals during lung development may have influenced mesenchymal growth, ultimately leading to the robust central fibrotic lesions. Finally, epithelial cells expressing SP-C and human TGF- $\alpha$ were readily detected within the epithelial cells in central fibrotic lesions, perhaps further contributing to the local production of TGF- $\alpha$, thereby producing the marked, central fibroproliferative responses observed in the lungs of the transgenic mice. There were no detectable abnormalities in epithelial cell distribution or in the incidence of pulmonary adenoma formation observed in the present study. The variability in severity and distribution of lesions observed in these mice may relate to differences in the level, timing, and/or distribution of expression of the TGF$\alpha$ transgene. Such heterogeneity was also observed in the SP-CCAT-bearing transgenic mice, in which the level and relative abundance of alveolar as compared to distal bronchiolar expression of the SP-C-driven transgene varied among founder lines (34).

Figure 4. $(A-H)$ In situ hybridization of hTGF- $\alpha$ and endogenous SP-C mRNA in peripheral lesions of lungs from the SP-C-hTGF- $\alpha$ transgenic mice. Dark-field and bright-field photomicrographs of lung periphery of SP-C-hTGF- $\alpha(A-D)$ and transgenic negative controls $(E-H)$. $A$ and $E$ were hybridized with the hTGF- $\alpha$ oligomer, while panels $C$ and $G$ were hybridized with a murine SP-C ribroprobe. Human TGF- $\alpha$ mRNA was detected only in the transgenic mice in a distribution consistent with SP-C expressing alveolar type II cells $(A$ and $C)$. Increased hybridization for both probes was noted in close association with pleural fibrotic lesions. Human TGF- $\alpha$ oligonucleotide did not bind to nontransgenic lung $(E$ and $F)$. Note disruption of alveolar architecture in the transgenic mice $(B$ and $D) . \sim \times 72$. 
Alveolar structure in the TGF- $\alpha$-bearing transgenic mice. While the interstitium of the alveoli was not detectably altered by light microscopy, the alveolar size was apparently increased in all of the TGF- $\alpha$-bearing transgenic mice studied, Fig. 2-4. This finding strongly supports the concept that the local production of TGF- $\alpha$ has influenced the morphogenesis, and in particular, the alveolar septation of these lungs. Recent in vitro studies by Ganser et al. (18) and Swantz et al. (35) demonstrated that TGF- $\alpha$ and EGF reduced the rate of lung bud formation in organ culture of fetal mouse lung. The present study and those of Ganser and Swantz provide support for the concept that this family of polypeptides interferes with branching morphogenesis of the lung and contrast with the work of Warburton et al. (8), who described increased branching of lung explants after treatment with EGF. Although detailed morphometric studies have not been performed, the present study suggests that alveolar septation may be decreased, rather than increased, during lung morphogenesis in the SP-C-TGF- $\alpha$ mice. Previous studies with the SP-C promoter element demonstrated that expression of the chimeric SP-C-CAT gene is maintained throughout the period of branching morphogenesis and alveolarization (27). Thus, local production of human TGF- $\alpha$ in the developing lung may have influenced alveolar organization and, ultimately, the structure of the lung in the adult transgenic animals.

There were also no consistent changes in mononuclear or polymononuclear cells in the lungs of the SP-C-TGF- $\alpha$ transgenic mice. Serologic studies from the mouse colony failed to identify common respiratory pathogens. The marked pulmonary fibrosis seen in the transgenic mice was not observed in control mice housed under identical conditions nor in numerous mice bearing SP-C chimeric transgenes that have been maintained in our colonies over the past $5 \mathrm{yr}$, as assessed visually and histologically. Thus, the lesions observed in the present study are related to the expression of TGF- $\alpha$ directed by the transgene.

Correlations with human pulmonary disease. Pulmonary fibrosis is a common consequence of diverse injuries to the lung. The pathologic features of pulmonary fibrosis are variable and highly dependent on the cause and degree of injury. After acute lung injury, inflammatory cells appear in the interstitium and airspaces, followed by epithelial changes and leakage of vascular components into the airspace and interstitium. The inflammatory responses may resolve entirely or lead to pulmonary fibrosis. Fibrotic lesions are initially hypercellular and contain abundant collagen then advance to thickened, collagen-filled interstitium and airspaces. A variety of cytokines and growth factors have been detected during the course of formation of fibrotic lung lesions. TGF- $\alpha$ is synthesized and released by alveolar macrophages and platelets within the lung after stimulation by lipopolysaccharides (23), and the local release of TGF- $\alpha$ may influence the fibrotic process during lung injury. Immunoreactive EGF is increased in the conducting airway epithelium of infants dying of bronchopulmonary dysplasia in association with severe pulmonary fibrosis (9), and TGF- $\alpha$ mRNA synthesis is increased in epithelial cells in rats after bleomycin-induced pulmonary fibrosis (24). The transgenic mouse model presented in the present study demonstrates that TGF- $\alpha$ expression leads to interstitial fibrotic lesions in the lung, but further studies are needed to identify epithelial cell TGF- $\alpha$ synthesis in a clinical injury. The pathological process in these transgenic mice is primarily fibroproliferative, involving interstitial regions and pleural surface, rather than peripheral airspaces. Although mononuclear cells, including macrophages, were detected in alveolar spaces in some of the mice, there was no marked inflammatory process in the lungs of these animals. A similar fibrotic response occurred to TGF- $\alpha$ in the pancreas of transgenic mice $(32,33)$ in the absence of inflammation. Thus, in the lung and pancreas, the fibroproliferative response can occur in the absence of severe inflammatory cell infiltration.

In summary, we have generated transgenic mice in which human TGF- $\alpha$ was expressed in the lung in an epithelial cellspecific manner. The mice developed pulmonary fibrosis, demonstrating that TGF- $\alpha$ produced by the lung epithelium causes a fibroproliferative response in the interstitium and pleural surface. These studies support the hypothesis that TGF- $\alpha$ or family members of the EGF receptor family may be mediators of pulmonary fibrosis after lung injury.

\section{Acknowledgments}

Supported by the Cystic Fibrosis Foundation, National Institutes of Health Perinatal Emphasis Research Center (HD20748), Program of Excellence Molecular Biology, Heart and Lung(HL41496), and American Lung Association (RG-182-N).

\section{References}

1. Carpenter, G., and S. Cohen. 1979. Epidermal growth factor. Annu. Rev. Biochem. 48:193-216.

2. Das, M., and C. F. Fox. 1978. Molecular mechanism of mitogen action: processing of receptor induced by epidermal growth factor. Proc. Natl. Acad. Sci. USA 75:2644-2648.

3. Cohen, S., and G. Carpenter. 1975. Human epidermal growth factor: isolation and chemical and biological properties. Proc. Natl. Acad. Sci. USA. 72:13171319.

4. Marquardt, T., M. W. Hunkapiller, L. E. Hood, and G. J. Todaro. 1984. Rat transforming growth factor I: structure and relation to epidermal growth factor. Science (Wash. DC). 223:1079-1082.

5. Derynk, R., A. B. Roberts, M. E. Winkler, E. Y. Chen, and D. V. Goeddel. 1984. Human transforming growth factor- $\alpha$ : precursor structure and expression in E. coli. Cell. 38:287-297.

6. Fox, C. F., and M. Das. 1979. Internalization and processing of the EGF receptor in the induction of DNA synthesis in cultured fibroblasts: the endocytic activation hypothesis. J. Supramol. Struct. 10:199-214.

7. Reynolds, F. H., G. J. Todaro, C. Fryling, and J. R. Stephenson. 1981. Human transforming growth factors (TGFs) induce tyrosine phosphorylation of EGF receptors. Nature (Lond.) 292:259-262.

8. Warburton, D., C. Seth, L. Shrum, P. G. Horcher, F. L. Hall, Z. Werb, and H. C. Slavkin. 1992. Epigenetic role of epidermal growth factor expression and signalling in embryonic mouse lung morphogenesis. Dev. Biol. 149:123-133.

9. Stahlman, M. T., D. N. Orth, and M. E. Gray. 1989. Immunocytochemical localization of epidermal growth factor in the developing human respiratory system and in acute and chronic lung disease in the neonate. Lab. Invest. 60:539547.

10. Raaberg, L., E. Nexo, J. Damsgaard Mikkelsen, and S. S. Poulsen. 1988. Immunohistochemical localization and developmental aspects of epidermal growth factor in the rat. Histochemistry. 89:351-256.

11. Raaberg, L., S. S. Poulsen, and E. Nexo. 1991. Epidermal growth factor in the rat lung. Histochemistry. 95:471-175.

12. Sannes, P. L., K. K. Burch, and J. Khosla. 1992. Immunohistochemical localization of epidermal growth factor and acidic and basic fibroblast growth factors in postnatal developing and adult rat lungs. Am. J. Respir. Cell. Mol. Biol. 7:230-237.

13. Strandjord, T. P., J. G. Clark, W. A. Hodson, R. A. Schmidt, and D. K. Madtes. 1993. Expression of transforming growth factor- $\alpha$ in mid-gestation human fetal lung. Am. J. Resp. Cell. Mol. Biol. 8:266-272.

14. Lee, D. C., R. Rochford, G. J. Todaro, and L. P. Villarreal. 1985. Developmental expression of rat transforming growth factor- $\alpha$ mRNA. Mol. Cell. Biol. 5:3644-3646.

15. Kubiak, J., M. M. Mitra, A. R. Steve, J. D. Hunt, P. Davies, and B. R. Pitt. 1992. TGF- $\alpha$ gene expression in late gestation fetal rat lung. Pediatr. Res. 31:286290.

16. Johnson, M. D., M. E. Gray, G. Carpenter, R. B. Pepinsky, H. Sundell, and $M$. T. Stahlman. 1989. Ontogeny of epidermal growth factor receptor/kinase and of lipocortin-1 in the ovine lung. Pediatr. Res. 25:535-541. 
17. Snead, M. L., W. Luo, P. Oliver, M. Nakamura, G. Don-Wheeler, C. Bessem, G. I. Bell, L. B. Pall, and H. C. Slavkin. 1989. Localization of epidermal growth factor precursors in tooth and lung during embryonic mouse development. Dev. Biol. 134:420-429.

18. Ganser, G. L., G. P. Stricklin, and L. M. Matrisian. 1991. EGF and TGF- $\alpha$ influence in vitro lung development by the induction of matrix-degrading metalloproteinases. Int. J. Dev. Biol. 35:453-461.

19. Sundell, H. W., M. E. Gray, F. S. Serenius, M. B. Escobedo, and M. T. Stahlman. 1980. Effects of epidermal growth factor on lung maturation in fetal lambs. Am. J. Pathol. 100:707-719.

20. Catterton, W. Z., M. B. Escobedo, W. R. Sexson, M. E. Gray, H. W. Sundell, and M. T. Stahlman. 1979. Effect of epidermal growth factor on lung maturation in fetal rabbits. Pediatr. Res. 13:104-108.

21. Plopper, C. G., J. A. St. George, L. C. Reed, S. Nishio, A. J. Weir, L. Edwards, A. F. Tarcental, K. E. Pinkerton, T. A. Merritt, and J. A. Whitsett. 1992. Acceleration of alveolar type II cell differentiation in fetal rhesus monkey lung by administration of EGF. Am. J. Physiol. 262:L313-321.

22. Whitsett, J. A., T. E. Weaver, M. A. Lieberman, J. C. Clark, and C. Daugherty. 1987. Differential effects of epidermal growth factor and transforming growth factor-B on synthesis of $\mathrm{Mr}=35,000$ surfactant-associated protein in fetal lung. J. Biol. Chem. 262:7908-7913.

23. Madtes, D. K., E. W. Raines, K. S. Sakariassen, R. K. Assoian, M. B. Sporn, G. I. Bell, and R. Ross. 1988. Induction of transforming growth factor- $\alpha$ in activated human alveolar macrophages. Cell. 53:285-293.

24. Madtes, D. K., H. K. Busby, T. P. Strandjord, and J. G. Clark. 1992. Transforming growth factor- $\alpha$ and epidermal growth factor receptor mRNA are increased following bleomycin-induced lung injury in rats. Am. Rev. Respir. Dis. 145:A848. (Abstr.)

25. Wispè, J. R., B. B. Warner, J. C. Clark, C. R. Dey, J. Neuman, S. W. Glasser, J. D. Crapo, L.-Y. Chang, and J. A. Whitsett. 1992. Human Mn-superoxide dismutase in pulmonary epithelial cells of transgenic mice confers protection from oxygen injury. J. Biol. Chem. 267:23937-23941.

26. Carson, F. L. 1990. Masson trichrome stain, Verhoeff's stain. In Histo- technology. A Self Instructional Text. ASCP Press/Chicago, IL. pp. 142-144 and 147-149.

27. Wert, S. E., S. W. Glasser, T. R. Korfhagen, and J. A. Whitsett. 1993. Transcriptional elements from the human SP-C gene direct expression in the primordial respiratory epithelium of transgenic mice. Dev. Biol. 156:426-443.

28. Brinster, R. L., J. M. Allen, R. P. Behringer, R. E. Gelinas, and R. D. Palmiter. 1988. Introns increase transcriptional efficiency in transgenic mice. Proc. Natl. Acad. Sci. USA. 85:836-840.

29. Bruce, M. C., M. Schuyler, R. J. Martin, B. C. Starcher, J. F. Tomashefski, and K. E. Wedig. 1992. Risk factors for the degradation of lung elastic fibers in the ventilated neonate. Am. Rev. Respir. Dis. 146:204-212.

30. Whitsett, J. A., C. R. Dey, B. R. Stripp, K. A. Wikenheiser, J. C. Clark, S. E. Wert, R. J. Gregory, A. E. Smith, J. A. Cohn, J. M. Wilson, and J. Engelhardt. 1992. Human cystic fibrosis transmembrane conductance regulator directed to respiratory epithelial cells of transgenic mice. Nature Genetics. 2:13-20.

31. Wikenheiser, K. A., J. C. Clark, R. I. Linnoila, M. T. Stahlman, and J. A. Whitsett. 1992. Simian virus 40 large $T$ antigen directed by transcriptional elements of the human surfactant protein $\mathrm{C}$ gene produces pulmonary adenocarcinomas in transgenic mice. Cancer Res. 52:5342-5352.

32. Jhappan, C., C. Stahle, R. N. Harkins, N. Fausto, G. H. Smith, and G. T. Merlino. 1990. TGF $\alpha$ overexpression in transgenic mice induces liver neoplasia and abnormal development of the mammary gland and pancreas. Cell. 61:11371146.

33. Sandgren, E. P., N. C. Luetteke, R. D. Palmiter, R. L. Brinster, and D. C. Lee. 1990. Overexpression of TGF $\alpha$ in transgenic mice: induction of epithelial hyperplasia, pancreatic metaplasia, and carcinoma of the breast. Cell. 61:11211135.

34. Glasser, S. W., T. R. Korfhagen, M. D. Bruno, C. Dey, and J. A. Whitsett. 1990. Structure and expression of the pulmonary surfactant protein SP-C gene in the mouse. J. Biol. Chem. 265:21986-21991.

35. Swantz, R. I. Fink, S. Wert, and T. Korfhagen. 1992. Transforming growth factor- $\alpha$ remodels tubule formation of murine fetal lungs in culture. $\mathrm{Pe}$ diatr. Pulmon. Suppl. 8:281. (Abstr.) 